\title{
Stage I Testicular Non-Seminomatous Germ Cell Tumor AJCC v6 and v7
}

National Cancer Institute

\section{Source}

National Cancer Institute. Stage I Testicular Non-Seminomatous Germ Cell Tumor A/CC

v6 and v7. NCI Thesaurus. Code C27785.

Stage I includes: PT 1-4, N0, M0, SX. PT 1: Tumor limited to the testis and epididymis without vascular/lymphatic invasion; tumor may invade into the tunica albug inea but not the tunica vag inalis. pT 2: Tumor limited to the testis and epididymis with vascular/lymphatic invasion, or tumor extending through the tunica albuginea with involvement of the tunica vag inalis. PT 3: T umor invades the spermatic cord with or without vascular/lymphatic invasion. pT 4: Tumor invades the scrotum with or without vascular/lymphatic invasion. N0: No regional lymph node metastasis. M0: No distant metastasis. SX: Marker studies not available or not performed. (AJCC 6th and 7th eds.) 